Cuadernos de Filología Clásica

Estudios griegos e indoeuropeos

ISSN: $1131-9070$

https://dx.doi.org/10.5209/cfcg.72824

\title{
La pérdida de un gran maestro: Francisco Rodríguez Adrados
}

El pasado 21 de julio falleció en Madrid, a los 98 años, el profesor Francisco Rodríguez Adrados, Catedrático de Filología Griega de nuestra Universidad desde 1952 hasta 1988. Nacido en Salamanca, el 29 de marzo de 1922, había estudiado Filología Clásica en su ciudad natal, donde se licenció en 1944, y se había doctorado en la entonces Universidad Central de Madrid, en 1946. Antes de alcanzar su destino en Madrid, fue Catedrático de Griego desde 1949 en el Instituto Cardenal Cisneros y durante un año (1951) Catedrático de la Universidad de Barcelona. Tras su jubilación en la Complutense fue elegido Catedrático Emérito.

Adrados pertenece a una generación de profesores españoles que tuvo que desarrollar su trabajo en medio de una extraordinaria penuria de medios, sin tradición en muchas especialidades (en su caso, los Estudios Clásicos), sin apenas libros en las bibliotecas, en un período en el que España aún se resentía de las terribles pérdidas de la Guerra Civil y en el que los colegas extranjeros mostraban un enorme desinterés, cuando no desprecio, por nuestro trabajo. Aún recuerdo que en los años sesenta, cuando la situación había mejorado bastante respecto a los primeros tiempos de la actividad de Adrados, para poder llevar a cabo los trabajos del Diccionario Griego Español, había que comisionar regularmente a un colaborador del Diccionario para que fuera a Oxford o a París un par de días para encerrarse en las bibliotecas, revisar una larga lista de citas, en ediciones que no teníamos en España, o venir cargado de fotocopias de textos imprescindibles.

Adrados combinó desde el primer momento la docencia y la investigación en Filología Clásica y en Lingüística Indoeuropea. Es curioso, porque aún la Lingüística Indoeuropea se integra en nuestra Facultad en el Departamento de Filología Clásica, lo que sin duda ha convertido en tradición la doble dedicación de Adrados y su forma filológica de concebir estos estudios. Su incansable labor, su conocimiento enciclopédico, contribuyeron decisivamente a crear y desarrollar una investigación seria en nuestra Universidad y en nuestro país, en medio de tan difíciles circunstancias. En todo momento se esforzó por incorporar a la universidad española los métodos de trabajo vigentes entonces en Europa y Norteamérica. Y ello, tanto en la investigación como en la docencia, actividades inseparables en su forma de entender su trabajo. En efecto, un atractivo especial de sus clases era que no se limitaba a transmitir ciencia adquirida, sino que incorporaba a sus enseñanzas las últimas novedades, aquello sobre lo que estaba trabajando, incluyendo sus propias aportaciones, lo que les prestaba un gran valor añadido.

Si se observan los trabajos de Adrados, tanto los de tema lingüístico como los filológicos o literarios, se advierte que en el trasfondo de su modo de investigar hay siempre un esquema bastante consistente: la observación y explicación de los hechos estudiados a través de dos coordenadas básicas, la estructura y la evolución. Estudia y presenta los hechos desde la doble perspectiva sincrónica y diacrónica, señalando 
cómo los fenómenos configuran un sistema, son interdependientes, en tanto que cada uno de ellos se relaciona de determinadas formas con los otros. Cada estructura conserva huellas de la estructura anterior y, como consecuencia de la evolución de los hechos parciales, contiene también desajustes que afectan al sistema hasta producir un cambio, a veces radical, y es el estudio de unos y otros el que permite comprender por qué tales cambios se producen. A esas dos coordenadas responde, tanto en su título como en su contenido, el monumental libro Evolución y estructura del verbo indoeuropeo, una de las aportaciones más importantes al estudio de este ámbito de la Lingüística comparada, un libro al que sin duda perjudicó el habitual problema de gran parte de la investigación de nuestro país: Hispanicum non legitur. Básicamente, se trata del método de la fonología diacrónica, pero que, mutatis mutandis, aplicó en otros terrenos, con el aporte añadido de un análisis filológico impecable de los hechos. Siguiendo estas directrices, supo reconstruir la compleja evolución que se produjo en Grecia en el paso de las formas preteatrales del mundo de la fiesta a las monumentales obras de Esquilo, Sófocles, Eurípides o Aristófanes, en Fiesta, comedia y tragedia, o trazar los vericuetos del paso del pensamiento arcaico a la filosofía y la democracia en Ilustración y política en la Grecia clásica, o determinar cómo se desarrolló la lírica desde los estadios preliterarios a las grandes creaciones de Píndaro en Orígenes de la lírica griega, o analizar el estudio del lenguaje filosófico en Grecia desde los Presocráticos y los Sofistas a los gramáticos posteriores, en algunos estudios recogidos en Palabras e ideas.

Por otra parte, su visión de la historia del mundo era profundamente helenocéntrica: Adrados amaba y admiraba a Grecia con una intensidad y una profundidad mayor que a cualquier otra cosa y ello lo llevó a interesarse por el antes y el después de Grecia; por una parte, la forma en que la Hélade recibió influjos de ámbitos externos, como el Próximo Oriente, pero imponiendo sobre ellos su propio sello cultural, y por otra, cómo Grecia permeó con su lenguaje, con sus recursos literarios, con su pensamiento filosófico, los saberes de las épocas posteriores, la cultura europea y más allá.

Pero, sobre todo, Adrados era un auténtico pathfinder. Nunca aceptó la comodidad de las "variaciones sobre el mismo tema" en terreno seguro, sino que buscó una y otra vez nuevos caminos en los que la investigación no se prodigaba, tanto en sus propias contribuciones como en las tesis que encargaba a sus discípulos. Y así lo hizo ya en su propia tesis sobre la fábula, un género prácticamente olvidado en la investigación de ese momento, que lo llevó a convertirse en el primer especialista mundial sobre la cuestión, o en su dedicación a la entonces naciente Micenología, que se concretó en numerosas publicaciones y en el encargo de una tesis sobre el léxico micénico a Francisco Aura, que fue luego publicada y es aún el libro de referencia en la cuestión. Ejemplos de esta apertura de nuevos caminos son también sus trabajos (y los de algunos de sus discípulos) sobre la estructura de las obras dramáticas, o sus estudios sobre la lengua hitita, cuya importancia para el conocimiento del Indoeuropeo advirtió desde un primer momento, y que le permitieron expresar su famosa propuesta de las fases de la historia de la protolengua, desde una fase preflexional al último de esos estratos, que sería el Indoeuropeo tradicionalmente reconstruido.

La amplitud de sus conocimientos le permitió además explorar otros terrenos más lejanos, pero siempre relacionados con el Griego, como se ve en la publicación de Aśoka, Edictos de la Ley Sagrada, traducción del prácrito, o en su interés por la presencia de textos griegos sapienciales en obras árabe-castellanas, o por la evolución del cuento erótico. En sus últimos años cultivó las grandes síntesis, como El Río de 
la literatura, o El Reloj de la Historia, en las que presentaba una panorámica, a vista de pájaro, sobre siglos de evolución de los hechos, de una forma que solo una persona con su saber enciclopédico y su capacidad de relación podía abordar.

No continúo por este camino. Cualquier intento de glosar la producción científica de Adrados, aun de forma muy resumida, ocuparía la extensión de todo el número de la Revista, como también sería sumamente difícil referirse con la extensión debida a sus aportaciones como miembro de las Academias de la Lengua Española y de la Historia, o enumerar el gran número de distinciones y honores con que se reconoció su trabajo. Prefiero referirme a otros aspectos de su caleidoscópica personalidad.

El primero de ellos es su conocido denuedo en defender los Estudios Clásicos y las Humanidades en general, que lo llevó a emplear innumerables horas en entrevistas con las más altas instancias ministeriales, que, cuando estaban medio convencidas, eran destituidas, lo que lo obligaba a comenzar otra vez, como en la tela de Penélope; innumerables horas también en promover manifiestos, hacer declaraciones en la prensa o en la televisión o escribir artículos sobre la cuestión, sin que el reiterado desinterés de las sucesivas autoridades ministeriales de uno u otro signo lo hiciera cejar un ápice en su esfuerzo constante.

Por otra parte debo señalar que su incansable capacidad de trabajo, que manifestaba en su habilidad de aprovechar los mínimos huecos del tiempo para avanzar en sus investigaciones, no le impedía cultivar otras aficiones, como los viajes o la conversación. Tengo el privilegio de haber participado en muchas conversaciones con Adrados, en las que manifestaba su enorme sentido del humor y cundían las anécdotas más divertidas, que recordaba con su prodigiosa memoria.

Y sobre todo ello, Adrados estaba dotado de una gran capacidad ilusionante, que supo atraer discípulos que trabajaron sobre sus métodos y continuaron su labor en los más diversos terrenos. Permítaseme una pequeña anécdota personal. Yo llegué a la Facultad de Filosofía y Letras, a los llamados "Comunes", con la decidida intención de estudiar Románicas, dado que me atraía enormemente la literatura española. Pero en $2^{\circ}$ de Comunes Adrados propuso un Seminario de Líricos Griegos, una de las múltiples actividades (como lo fuera también su primer seminario de sánscrito) promovidas por él fuera de su dedicación docente por su deseo de transmitir conocimientos. Tras asistir al Seminario de Líricos, terminé con dos convicciones nuevas: estudiar Filología Clásica y trabajar con el Profesor Adrados. Felizmente pude cumplirlas ambas.

$\mathrm{Y}$ es que Adrados poesía algunas cualidades tan notables como poco frecuentes: su profundo convencimiento del carácter compartido, colectivo, del saber, un entusiasmo contagioso y una generosidad sin límites, que lo llevaron a propiciar múltiples actividades y a atraer a alumnos que se incorporaron a estos nuevos caminos con el mismo entusiasmo, y en medio de un notable sentido de libertad. Trató siempre a sus discípulos con respeto, escuchándonos cuando las conclusiones a las que llegábamos diferían de las suyas, y discutiendo sin imposiciones las alternativas. Sabía trabajar en equipo, como se demostró en la creación del grupo de colaboradores del Diccionario Griego Español, opus magnum cuyo desarrollo fue posible por su capacidad de escuchar, de convencer, de liderar sin imposiciones, de aunar criterios. Recuerdo las estupendas reuniones, en las que quienes trabajábamos en el Diccionario cambiábamos impresiones, cada uno desde su parcela de trabajo, para buscar una dirección común del trabajo. O los cenáculos que propició en su casa de Turégano, en los que participaban desde catedráticos a los más jóvenes doctorandos 
(de su escuela o fuera de ella), cada uno de los cuales exponía informalmente experiencias del trabajo que estaban realizando, y de este modo contrastaba sus puntos de vista con los de los demás.

Toda esta actividad se veía facilitada, además, por su inmensa vitalidad. Hasta edad muy avanzada lo he visto fatigar a grupos de viajeros, cuesta arriba, a la busca de un perdido rincón de un sitio arqueológico, jugar al frontón en el muro del Castillo de Turégano o nadar en diversos mares, en especial, los griegos, a los que tanto amaba.

Lo echaremos siempre de menos. Nos hemos quedado un poco más huérfanos sin su magisterio, sus inmensos saberes, su generosidad científica, su sentido del humor y su amistad. Descanse en paz, con la satisfacción de la obra bien hecha y de la imborrable huella que ha dejado sobre nuestros estudios y nuestros estudiosos.

Alberto Bernabé Pajares Universidad Complutense de Madrid, Departamento de Filología Clásica albernab@ucm.es 